Pramāna, Vol. 16, No. 5, May 1981, pp. 385-390. (C) Printed in India.

\title{
Crystal structure of ethyl pyruvate-2-methyl-4-chloro-phenyl hydrazone
}

\author{
K RAVINDRA ACHARYA and D S SAKE GOWDA* \\ Department of Physics, Central College, Bangalore University, Bangalore 560 001, \\ India \\ *Present address: Department of Chemistry, Adelphi University, Garden City, \\ New York 11530, USA
}

MS received 12 November 1980; revised 4 March 1981

\begin{abstract}
Ethyl pyruvate-2-methyl-4-chloro-phenylhydrazone, $\mathrm{C}_{12} \mathrm{H}_{15} \mathrm{~N}_{2} \mathrm{O}_{2} \mathrm{Cl}$, is an important intermediate for the synthesis of ethyl-5-chloro-7-methyl indole-2-carboxylate. Crystals are orthorhombic with $a=6.99(4), b=23.75(6), c=17.05(6) \AA$ and eight molecules per cell in the space group Cmca. The structure was solved by direct methods using film data and refined by block diagonal least squares method to an $R$-index of 0.052 . The molecule occupies the space group mirror $(m)$ special position. The stacking of the molecules is stabilized by van der Waal's contacts.
\end{abstract}

Keywords. Phenylhydrazone; crystal structure; direct methods; special position.

\section{Introduction}

As a part of our studies of the indole field, the crystal structure determination of the above compound was undertaken. The title compound is an important intermediate for the synthesis of ethyl-5-chloro-7-methyl indole-2-carboxylate (Ambekar and Siddappa 1965) which is the starting material for the synthesis of 5-methyl-7-chloroindole and its derivatives which are of biological interest for their anti-tubercular activity. The compound ethylpyruvate-2-methyl-4-chloro-phenylhydrazone hereafter referred as EMCPH has been obtained synthetically via Japp-Klingemann reaction (Holla 1979). The compound in its pure form was gifted by Dr S Y Ambekar of Mysore University, Mysore, India.

\section{Experimental}

Yellow coloured transparent crystals, elongated along (100) were grown by slow evaporation of a hexane solution. The space group and unit cell dimensions were determined from $x$-ray diffraction photographs and the density was measured by floatation in a mixture of bromobenzene and kerosene.

Crystal data, ethylpyruvate-2-methyl-4-chloro-phenylhydrazone, $\mathrm{C}_{12} \mathrm{H}_{15} \mathrm{~N}_{2} \mathrm{O}_{2} \mathrm{Cl}$,

$$
\text { M. wt. }=254 \cdot 7, a=6.99(4), b=23.75(6), c=17 \cdot 05(6) \AA \text {, }
$$


$v=2834.6 \AA^{3}, \quad D_{m}=1 \cdot 20, \quad D_{c}=1.19 \mathrm{Mg} \mathrm{m}^{-3}, \quad Z=8, \quad \mu=22.31 \mathrm{~cm}^{-1}$ for $\lambda=1.5418 \AA$, M. pt. $=391 \mathrm{~K}$.

Systematic absences $h k l: h+k=2 n ; h 0 l: l=2 n ;(h=2 n) ; h k 0: h=2 n$; $(k=2 n)$ correspond to space group Cmca or C2ca of which the former was chosen, being strongly favoured by the intensity statistics.

A crystal of dimensions $1 \times 1 \times 1 \mathrm{~mm}$ was used for collecting $x$-ray intensity data for layers $h k l(h=0$ to 5) by equi-inclination Weissenberg technique using Nifiltered $\mathrm{CuK}_{\alpha}$ radiation. The intensities were estimated by comparing a set of standard spots prepared with the same crystal. The data, corrected for Lorentz, polarisation and spot shape factors and not for absorption, were placed on an absolute scale by Wilson's method. Out of 912 reflections observed within the region surveyed, 297 were too low to be measured.

The structure was solved using 'SHELX-76' program (Sheldrick 1976). An E-map computed using $E$-values greater than 1.2 revealed all the non-H atoms. The structure was refined by block diagonal least squares methods using a Program set (Shiono 1968 ) on the DEC-1090 system. The $R$-factor at the end of isotropic refinement for all the non-H atoms was 0.131. At this stage, the refinement was continued with anisotropic temperature factors with constraints imposed as per the space group symmetry (Johnson and Levy 1974). The $R$-factor at the end of the anisotropic refinement for non- $\mathrm{H}$ atoms stood at $\mathbf{0 . 0 5 6}$. The positions of the $\mathrm{H}$ atoms were fixed at this stage from geometrical considerations by comparison with similar structures and with the aid of a difference Fourier map. These atoms were assumed to have the same isotropic temperature factors as those of the heavier atoms to which they were attached. The $\mathrm{H}$ atoms were included in the structure factor calculations in the subsequent SFLS cycles, but only the positional parameters of the $\mathrm{H}$ atoms, the positional and the anisotropic thermal parameters of the non- $\mathrm{H}$ atoms were refined. The refinement was terminated at $R=0.052$ when all the least-squares shifts were lower than the corresponding standard deviations. The weighting scheme of Cruickshank et al (1961) was applied at the later stages of refinement. The form factors of the non- $\mathrm{H}$ atoms and the $\mathrm{H}$ atoms were taken from Cromer and Waber (1965) and Stewart et al (1965) respectively. The final positional parameters of the non- $\mathrm{H}$ atoms and the $\mathrm{H}$ atoms are given in tables 1 and 2 respectively. Final anisotropic temperature factors for all the non-H atoms are given in table 3. The values of observed and calculated structure factors can be supplied by the authors on request.

\section{Discussion}

EMCPH belongs to the general family of ethylpyruvate phenylhydrazone having 'syn' and 'anti' conformations due to hydrogen bonding as shown in figure 1 . The structure of EMCPH by $x$-ray analysis (figure 2), confirms the presence of non-hydrogen bonded $a$-form of the molecule in the solid state. Also the fact that $N(2)$ in the structure does not carry a hydrogen and that no hydrogen bond in the 'syn' conformation between $\mathrm{N}(2)$ and $\mathrm{O}(1)$ is possible, thus makes the 'anti' conformation more energetically favourable. Similar structural features have been observed with ethyl- $a$ (phenylhydrazono) furan-2-propionate (hereafter referred as EPHFP), the crystal structure of which has also been established in our laboratory, with greater precision 
Table 1. Positional parameters $\left(\times 10^{4}\right)$ with standard deviations for non-hydrogen atoms

\begin{tabular}{llrl}
\hline Atom & $x$ & $y$ & $z$ \\
\hline $\mathrm{C} 1(1)$ & 0 & $3383(2)$ & $4688(2)$ \\
$\mathrm{O}(1)$ & 0 & $-554(6)$ & $2052(7)$ \\
$\mathrm{O}(2)$ & 0 & $-148(5)$ & $3233(7)$ \\
$\mathrm{N}(1)$ & 0 & $1436(4)$ & $2356(6)$ \\
$\mathrm{N}(2)$ & 0 & $873(5)$ & $2662(6)$ \\
$\mathrm{C}(1)$ & 0 & $1880(5)$ & $2926(7)$ \\
$\mathrm{C}(2)$ & 0 & $2465(5)$ & $2616(7)$ \\
$\mathrm{C}(3)$ & 0 & $2903(5)$ & $3206(7)$ \\
$\mathrm{C}(4)$ & 0 & $2809(7)$ & $3987(9)$ \\
$\mathrm{C}(5)$ & 0 & $2222(8)$ & $4307(9)$ \\
$\mathrm{C}(6)$ & 0 & $1779(7)$ & $3716(9)$ \\
$\mathrm{C}(7)$ & 0 & $2569(6)$ & $1713(8)$ \\
$\mathrm{C}(8)$ & 0 & $467(6)$ & $2150(8)$ \\
$\mathrm{C}(9)$ & 0 & $-142(6)$ & $2466(10)$ \\
$\mathrm{C}(10)$ & 0 & $-750(8)$ & $3588(10)$ \\
$\mathrm{C}(11)$ & 0 & $-725(10)$ & $4356(12)$ \\
$\mathrm{C}(12)$ & 0 & $526(8)$ & $1200(10)$ \\
\hline
\end{tabular}

Table 2. Positional parameters $\left(\times 10^{3}\right)$ with standard deviations for hydrogen atoms and isotropic thermal parameters

\begin{tabular}{lcccc}
\hline & $x$ & $y$ & $z$ & Biso \\
\hline H(C3) & 0 & $328(7)$ & $290(9)$ & $2 \cdot 9$ \\
H(C5) & 0 & $216(6)$ & $487(9)$ & $4 \cdot 2$ \\
H(C6) & 0 & $134(6)$ & $383(8)$ & $4 \cdot 5$ \\
H(C7a) & $117(3)$ & $282(8)$ & $158(10)$ & $3 \cdot 6$ \\
H(C7b) & 0 & $224(6)$ & $155(8)$ & $3 \cdot 6$ \\
H(C7c) & $-117(3)$ & $282(8)$ & $158(10)$ & $3 \cdot 6$ \\
H(C10a) & $-120(3)$ & $-95(8)$ & $340(11)$ & $4 \cdot 7$ \\
H(C10b) & $120(3)$ & $-95(8)$ & $340(11)$ & $4 \cdot 7$ \\
H(C11a) & $-123(3)$ & $-50(8)$ & $457(10)$ & $3 \cdot 5$ \\
H(C11b) & 0 & $-112(6)$ & $452(9)$ & $3 \cdot 5$ \\
H(C11c) & $123(3)$ & $-50(8)$ & $457(10)$ & $3 \cdot 5$ \\
H(C12a) & $113(3)$ & $72(8)$ & $105(11)$ & $3 \cdot 6$ \\
H(C12b) & 0 & $16(6)$ & $94(9)$ & $3 \cdot 6$ \\
H(C12c) & $-113(3)$ & $72(8)$ & $105(11)$ & $3 \cdot 6$ \\
H(N1) & $95(3)$ & $133(8)$ & $209(10)$ & $4 \cdot 4$ \\
\hline
\end{tabular}

using diffractometer data (Puttaraja et al 1980). The EPHFP molecule too has nonhydrogen bonded, $a$-form.

The crystal structure of EMCPH viewed down $a$-axis is shown in figure 3 . The molecule occupies the space group $(m)$ special position. All atoms in the molecule lie in mirror planes at $x=0.0$ and $x=0.5$ and the molecule as a whole (except for the hydrogens belonging to the methyl and ethyl groups) is necessarily planar. Similar observations have been made in pyrimidine hydrochloride (Furberg and Aaas 1975) 
Table 3. The anisotropic thermal parameters $\left(\times 10^{4}\right)$ for all non-hydrogen atoms.

\begin{tabular}{lrrrrrr}
\hline Atom & $B_{\mathbf{1 1}}$ & $B_{\mathbf{2 2}}$ & $B_{\mathbf{3 3}}$ & $\boldsymbol{B}_{\mathbf{1 2}}$ & $\boldsymbol{B}_{\mathbf{1 3}}$ & $B_{\mathbf{2 3}}$ \\
\hline $\mathrm{Cl}(1)$ & $233(10)$ & $16(1)$ & $17(1)$ & 0 & 0 & $-2(1)$ \\
$\mathrm{O}(1)$ & $328(36)$ & $22(3)$ & $22(5)$ & 0 & 0 & $-1(2)$ \\
$\mathrm{O}(2)$ & $557(46)$ & $14(2)$ & $15(4)$ & 0 & 0 & $1(3)$ \\
$\mathrm{N}(1)$ & $27(24)$ & $8(2)$ & $9(4)$ & 0 & 0 & $1(2)$ \\
$\mathrm{N}(2)$ & $26(27)$ & $16(2)$ & $18(5)$ & 0 & 0 & $-1(3)$ \\
$\mathrm{C}(1)$ & $18(28)$ & $9(2)$ & $10(5)$ & 0 & 0 & $-1(3)$ \\
$\mathrm{C}(2)$ & $24(29)$ & $9(2)$ & $11(5)$ & 0 & 0 & $2(3)$ \\
$\mathrm{C}(3)$ & $11(26)$ & $5(2)$ & $5(4)$ & 0 & 0 & $-1(2)$ \\
$\mathrm{C}(4)$ & $69(31)$ & $18(3)$ & $18(6)$ & 0 & 0 & $1(4)$ \\
$\mathrm{C}(5)$ & $61(34)$ & $25(4)$ & $24(7)$ & 0 & 0 & $4(5)$ \\
$\mathrm{C}(6)$ & $107(34)$ & $16(3)$ & $18(6)$ & 0 & 0 & $2(3)$ \\
$\mathrm{C}(7)$ & $73(30)$ & $13(3)$ & $14(5)$ & 0 & 0 & $-1(3)$ \\
$\mathrm{C}(8)$ & $43(33)$ & $15(3)$ & $16(5)$ & 0 & 0 & $-1(3)$ \\
$\mathrm{C}(9)$ & $153(37)$ & $14(3)$ & $15(5)$ & 0 & 0 & $-5(4)$ \\
$\mathrm{C}(10)$ & $1033(34)$ & $11(3)$ & $13(6)$ & 0 & 0 & $-4(4)$ \\
$\mathrm{C}(11)$ & $708(37)$ & $24(5)$ & $25(8)$ & 0 & 0 & $-3(6)$ \\
$\mathrm{C}(12)$ & $442(58)$ & $15(3)$ & $17(6)$ & 0 & 0 & $-1(4)$ \\
\hline
\end{tabular}

The temperature factor is expressed as

$U=\exp \left[-\left(B_{11} h^{2}+B_{22} k^{2}+B_{33} l^{2}+2 h k B_{12}+2 h l B_{13}+2 k l B_{23}\right)\right]$<smiles>CCOC(=O)C(C)=NNc1ccc(Cl)cc1C</smiles>

(a)<smiles>CCOC(=O)CN1N=C(C)CO1</smiles>

(b)

Figure 1. (a) Anti- or a-form and (b) Syn- or $\beta$-form of EMCPH molecule.

and N-(p-tolyl)-tetrachlorophthalimide (Kaftory 1978) which crystallize in the Cmca space group. The molecule has a layer structure perpendicular to $a$-axis. There is no hydrogen bonding, the molecules being loosely packed by van der Waal's contacts. The variations in bond lengths and bond angles are significant when compared to EPHFP and other related crystal structures. The conformation of the ester group 
$\mathrm{Cl}$<smiles>CCCC1CCCCC1C</smiles>

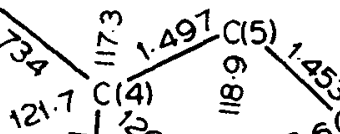

(1)

Figure 2. Bond lengths $(\AA)$ and bond angles $\left({ }^{\circ}\right)$ of the EMCPH molecule viewed down the $a$ axis. $\sigma$ bond length: 0.015 to $0.027 \AA, \sigma$ bond angle: 0.8 to $1.3^{\circ}$.

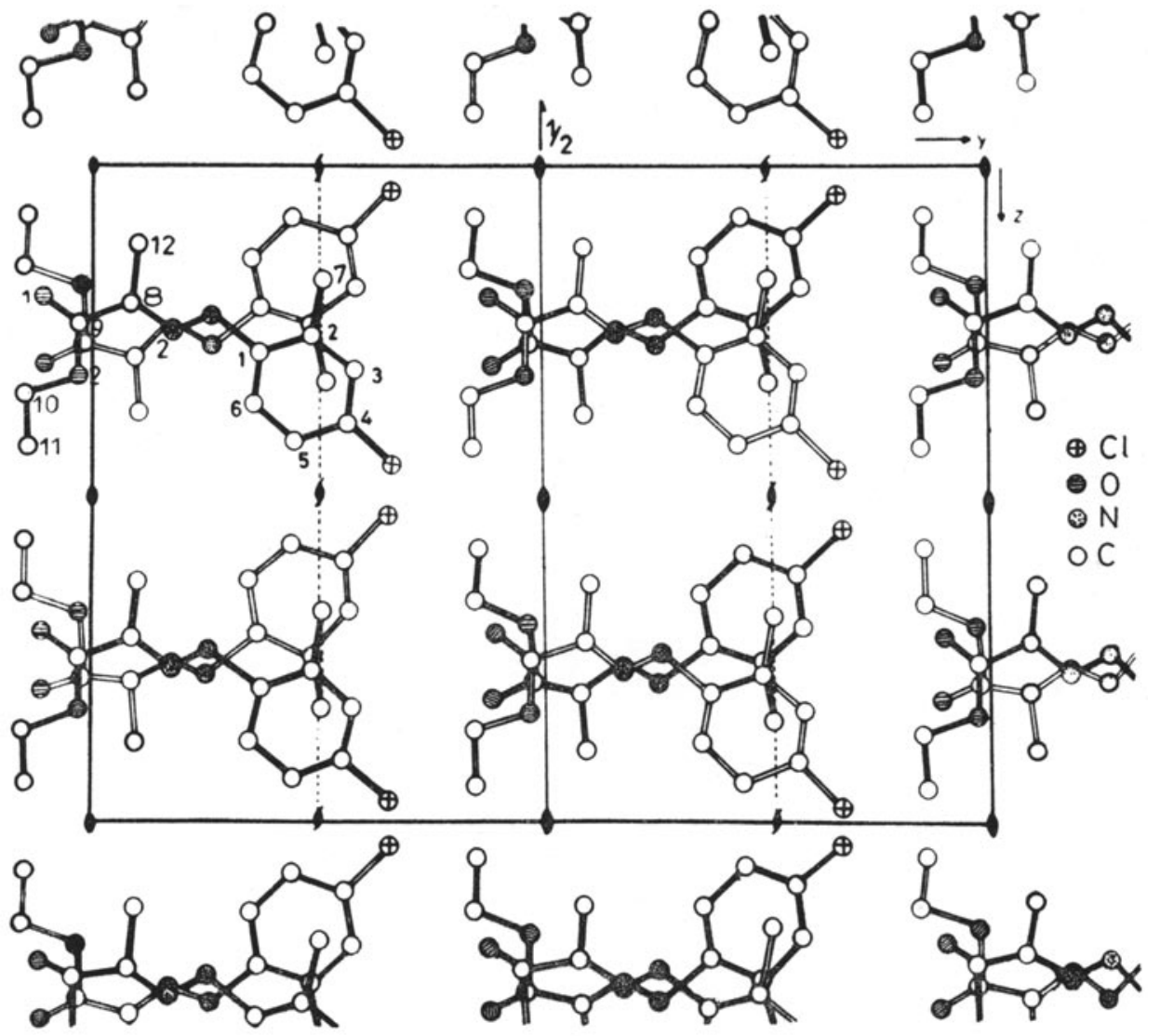

Figure 3. The Structure of EMCPH compound in a projection. Molecules at $x=0$ in open lines, at $x=0.5$ in heavy lines. 
agrees quite satisfactorily with the average values and standard conformation derived from available structural evidence of esters. The evidence regarding the ester group indicates that it is planar, that the nominally single $\mathrm{C}-\mathrm{O}$ bond lengths differ by $0.2 \AA$, that the angles $\mathrm{C}-\mathrm{O}-\mathrm{C}$ and $\mathrm{O}-\mathrm{C}-\mathrm{C}$ are in the range of $108-115^{\circ}$ and that the ester moiety is cis to the $\mathrm{C}=\mathrm{O}$ group (Aleby and von Sydow 1960).

\section{Acknowledgement}

The authors thank Professor K N Kuchela, Department of Physics, Bangalore University and Dr H M Krishna Murthy, Indian Institute of Science, Bangalore for their interest in the work. KRA is indebted to the Council of Scientific and Industrial Research, India for a fellowship.

\section{References}

Aleby S and von Sydow E 1960 Acta Crystallogr. 13487

Ambekar S Y and Siddappa S 1965 J. Karnataka Univ. Sci. 95

Cromer D T and Waber J T 1965 Acta Crystallogr. 18104

Cruickshank D W T, Bujosa A, Lovell F M and Truter M R 1961 Univ. of California Program, UCLALS 1

Furberg S and Aaas J B 1975 Acta Chim. Scand. A29 713

Holla B S 1979 Ph.D. Thesis, University of Mysore, (submitted)

Johnson C K and Levy H A 1974 International tables for $x$-ray crystallography (Birmingham: Kynoch Press) Vol. 4

Kaftory M 1978 Acta Crystallogr. B34 471

Puttaraja, Sake Gowda D S and Gabe E J 1980 unpublished work

Sheldrick G M 1976 The SHELX-76 program system, University Chemical Laboratory, Cambridge

Shiono R 1968 IISc Crystallographic Programs revised by Reddy S

Stewart R F, Davidson E R and Simpson W T 1965 J. Chem. Phys. 423175 